\title{
The balancing of NO concentration fluctuations by adsorption/desorption process on activated carbon
}

\author{
I. Potyková, L. Obalová*, L. Kuboňová, K. Obroučka \\ VŠB-Technical University of Ostrava, Centre for Environmental Technology, 17. listopadu \\ 15/2172, 70833 Ostrava, Czech Republic
}

\begin{abstract}
The present work deals with adsorption/desorption process of NO on activated carbon. The goal of the experiments was to determine under which conditions is the activated carbon bed able to damp down the concentration fluctuations of NO in the gas entering the bed. It was found out that the residence time necessary to balance out the input concentration fluctuations of NO increases along with the average concentration of NO. The minimum mean residence time of 3-9 min was found as necessary to level the average NO concentration ranging from 357-1428 ppm. The decisive parameters for the extent of attenuation are discussed in the terms of linear driving force model for fixed-bed adsorber dynamics.
\end{abstract}

Key words: NO, Adsorption, Activated carbon, Concentration balancing

*Corresponding author. Fax: +420 597323396. E-mail address: lucie.obalova@vsb.cz (L. Obalová) 


\section{Nomenclature}

$b$

c

$\bar{c}$

$\bar{c}^{o}$

$c^{0}$

$D_{\mathrm{L}}$

$k$

$K_{F}$

$L$

$m$

$n$

$q$

$q^{*}$

$q_{\mathrm{s}}$

$q^{o}$

$t$

$v_{0}$

$z$

$\varepsilon$

$\tau$

$\tau_{\text {cycle }}$

$\tau_{\mathrm{NO}}$
Langmuir adsorption equilibrium constant $\left(\mathrm{cm}^{3} \mathrm{~g}^{-1}\right)$

NO concentration in the gas phase $\left(\mathrm{g} \mathrm{cm}^{-3}\right)$

measured NO concentration at the column outlet, averaged per cycle duration (ppm)

calculated NO concentration at the column inlet, averaged per cycle duration (ppm)

NO concentration at the column inlet $\left(\mathrm{g} \mathrm{cm}^{-3}\right)$

axial dispersion coefficient $\left(\mathrm{cm}^{2} \mathrm{~s}^{-1}\right)$

mass-transfer coefficient $\left(\mathrm{s}^{-1}\right)$

adsorption coefficient for Freundlich isotherm $\left(\mathrm{mg} / \mathrm{g}(1 / \mathrm{mg})^{1 / \mathrm{n}}\right)$

length of adsorbent bed $(\mathrm{cm})$

distribution coefficient of NO in an gas-solid system

Freundlich constant (-)

NO concentration in adsorbent $\left(\mathrm{g} \mathrm{cm}^{-3}\right)$

equilibrium concentration of NO in adsorbent $\left(\mathrm{g} \mathrm{cm}^{-3}\right)$

Langmuir constant related to adsorption capacity $\left(\mathrm{g} \mathrm{cm}^{-3}\right)$

concentration of $\mathrm{NO}$ in adsorbent at initial conditions $\left(\mathrm{g} \mathrm{cm}^{-3}\right)$

time (s)

superficial gas velocity $\left(\mathrm{cm} \mathrm{s}^{-1}\right)$

distance from the inlet of the bed $(\mathrm{cm})$

bed voidage (-)

residence time (min)

duration of cycle (min)

part of cycle when NO- $\mathrm{N}_{2}$ mixture flows through the column (min) 


\section{Introduction}

Recently, it was found that a bed of activated carbon (AC) saturated with vapors of volatile organic compounds is under certain circumstances able to effectively damp the periodically repeating changes of concentration in the gas at the bed inlet [1]. The condition for balancing the concentration at the outlet of the adsorbent bed is to delay the flowing gas in the adsorbent layer for a sufficient time. This was determined experimentally on a laboratory model. Handling of fluctuating input load was also observed in the case of methyl ethyl ketone biodegradation in compost and activated carbon $[2,3]$.

The goal of the present work is the experimental verification of the usefulness of this method for balancing the fluctuating concentrations of NO and theoretical analysis of observed results. The problem of lowering the stable concentration of $\mathrm{NO}_{\mathrm{x}}$ emissions in waste gases from continual processes was successfully solved. The lowering of emissions in waste gases where the concentration is not stable and fluctuates in the range of several orders of magnitude, like for example in periodic processes, is very problematic. Time-variable concentrations of $\mathrm{NO}_{\mathrm{x}}$ with high deviations are present for example in waste gases from the catalyst production technology, the dissociation of molybdenum nuclei during lightbulb manufacture or the polishing of aluminum or jewellery in $\mathrm{HNO}_{3}$ solution. If the deviations of $\mathrm{NO}_{\mathrm{x}}$ concentrations in these waste gases were balanced out, it would be possible to use conventional methods for lowering the $\mathrm{NO}_{\mathrm{x}}$ emissions.

Despite a lot of efforts dealing with laboratory research of $\mathrm{NO}_{\mathrm{x}}$ adsorbents [4-6], activated carbon is still the most studied [7-9] and also commercially available adsorbent. From that reason it was selected as an adsorbent for the purpose of this work.

The mechanism of $\mathrm{NO}_{\mathrm{x}}$ adsorption is very complex; depending on the adsorbent type, physical adsorption of $\mathrm{NO}$ and $\mathrm{NO}_{2}$ or chemisorption of $\mathrm{NO}$ and $\mathrm{NO}_{2}$ leading to $\mathrm{NO}_{2}$ reduction, oxidation of NO and other reactions [10]. 
The subject of this work is to experimentally determine the minimum residence time of gas in the activated carbon bed necessary to balance out the selected fluctuation mode of inlet NO concentration. The mathematic model of dynamic adsorption process in fixed bed and equilibrium data of $\mathrm{NO}$ adsorption on $\mathrm{AU}$ obtained from breakthrough profiles are used to determine the decisive parameters under which input fluctuation is significantly attenuated. Nitric oxide and pure nitrogen as the carrier gas was selected as the simplest model system in order to prevent oxidation of $\mathrm{NO}$ to $\mathrm{NO}_{2}$ by air oxygen.

\section{Theory}

Simplified linear driving force (LDF) approach, used previously for simulation of biofilter for VOC degradation $[1,2]$, is adopted for modeling the NO adsorber performance. The model is based on the following assumptions:

- isothermal isobaric adsorption and ideal gas law are applied for the gas phase

- $\quad$ an axially dispersed plug flow through the AU packed bed

- no chemical reaction

Following equations constitute the LDF model:

Mass balance of NO in gas phase. This balance expresses the NO amount depleted from the gas phase by equating it to the transported gas phase to the adsorbent phase.

$$
\frac{\partial c}{\partial t}=D_{L} \frac{\partial^{2} c}{\partial z^{2}}-v_{0} \frac{\partial c}{\partial z}-\frac{1-\varepsilon}{\varepsilon} \mid \mathbf{q}^{*}-q_{-}^{-}
$$

Boundary conditions: $\left.D_{L} \frac{\partial c}{\partial z}\right|_{z=0}=-v_{0} \boldsymbol{\iota}^{o}-c,\left.\quad \frac{\partial c}{\partial z}\right|_{z=L}=0$

Initial condition: $c(\mathrm{z}, 0)=0$

Mass balance of $N O$ in adsorbent. This balance indicates that the rate of NO accumulated in adsorbent is equal to the NO transport rate into the adsorbent. 
$\frac{\partial q}{\partial t}=k \mathbf{q}^{*}-q$

Boundary conditions: $\left.\frac{\partial q}{\partial z}\right|_{z=0}=0,\left.\frac{\partial q}{\partial z}\right|_{z=L}=0$

Initial condition: $q(\mathrm{z}, 0)=0$

Generally, LDF mass-transfer coefficient $k$ is dependent on external mass transfer resistance, macropore and micropore mass transfer resistance.

Adsorption isotherm. Linear (3), Langmuir (4) and Freundlich (5) models are usually used for equilibrium description $[2,3,11]$ and are tested in this work.

$q=c / m$

$\frac{q^{*}}{q_{s}}=\frac{b c}{1+b c}$

$q=K_{\mathrm{F}} c^{1 / \mathrm{n}}$

\section{Experimental procedures}

\subsection{Materials}

Commercial granulated activated carbon (Resorbent, Czech Republic), was used as the adsorbent without any pre-treatment $\left(1124 \mathrm{~m}^{2} \mathrm{~g}^{-1}\right.$ specific surface area, $0.39 \mathrm{~nm}$ mean pore radius and $0.428 \mathrm{~cm}^{3} \mathrm{~g}^{-1}$ volume of micropores).

\subsection{NO adsorption equilibrium measurements}

For NO breakthrough curves measurements, the gaseous mixture (certified calibration gases of $0.0796,0.2900$ and $0.9970 \mathrm{~mol} \% \mathrm{NO}$ ) was passed through the AC bed (0.8 g AC, column diameter of $0.5 \mathrm{~cm}$, particle diameter of $1 \mathrm{~mm}$ or $1430 \mathrm{~g} \mathrm{AU}$, column diameter of $5 \mathrm{~cm}$, particle diameter of $4 \mathrm{~mm}$ ) at a flow-rate of $30-500 \mathrm{ml} \mathrm{min}^{-1}$ until saturation. Quadrupole 
mass spectrometer RGA 200 (SRS) and an Ultramat 6 infrared NO analyzer (Siemens) was used for NO analysis.

\subsection{NO adsorption/desorption experiments for balancing of NO concentration fluctuations}

The experimental laboratory apparatus for studying adsorption/desorption processes of NO consists of three sections: (i) the system of dosing, mixing and simulation of concentration fluctuations of NO in the carrier gas, (ii) the adsorption column with the adsorbent and (iii) the analytic section. The flow of pure NO (99.9 vol\%) was regulated by a mass-flow controller (Aalborg), $\mathrm{N}_{2}$ flow was regulated by a needle valve and monitored by a rotameter. The flow controller was connected to a programmable time switch for the simulation of NO concentration fluctuations.

The glass adsorption column with $5 \mathrm{~cm}$ i.d. was poured with $1430 \mathrm{~g}$ of AC (particle diameter of $4 \mathrm{~mm}$ ) leading to the bed height of $145 \mathrm{~cm}$. All measurements were done by using the same batch of AC. An Ultramat 6 infrared NO analyzer (Siemens) equipped with a catalytic $\mathrm{NO}_{2} / \mathrm{NO}$ converter was used for the analysis of $\mathrm{NO}_{\mathrm{x}}$ at the outlet of the adsorption column. The concentration of NO at the inlet of the adsorption column was determined by a calculation from $\mathrm{NO}$ and $\mathrm{N}_{2}$ volume flows.

The measurements of NO adsorption/desorption were carried out in 7-hours repeated cycles, when NO- $\mathrm{N}_{2}$ mixture flowed through the $\mathrm{AC}$ bed for the certain time period and pure $\mathrm{N}_{2}$ flowed during the rest time of 7 hours cycle. Concentration deviations of 1 mol\% NO (13.4 $\mathrm{g} \mathrm{m}^{-3}$ ) were applied. The mean residence time of the gas in column was $5-10 \mathrm{~min}$ at superficial velocity of $15.4-61.8 \mathrm{~cm} \mathrm{~min}^{-1}$, which was accounted to gas flow of $18 \mathrm{dm}^{3} \mathrm{~h}^{-1}-$ $30 \mathrm{dm}^{3} \mathrm{~h}^{-1}$ (measured at laboratory conditions). After changing the process parameters, the adsorption column was allowed to reach quasi-steady state for minimally 2 cycles, after that the damping of the periodically repeating changes of NO concentration was considered. 


\section{Results and discussion}

\subsection{Analysis of breakthrough curves}

Fig. 1 shows the breakthrough curves of $\mathrm{NO}$ at different initial concentrations. Formation of $\mathrm{NO}_{2}$ was observed at the beginning of the experiment with the freshly-poured $\mathrm{AC}$ which occurred due to the oxidation of $\mathrm{NO}$ by oxygen present in the pores of activated carbon. After all the oxygen was depleted, the formation of $\mathrm{NO}_{2}$ stopped. To determine gassolid adsorption equilibrium data, the dynamic column breakthrough (DCBT) method was adopted $[2,3]$. The adsorption capacity of AU for NO was evaluated by numerical integration of data. Linear, Langmuir and Freundlich model isotherms were tested for equilibrium description. It was observed that Langmuir isotherm fits the best (correlation coefficient $R^{2}=$ 0.99), constants obtained from linearized plot of $C / q$ vs. $C$ were $q_{\mathrm{s}}=1.02 .10^{-3} \mathrm{~g} / \mathrm{cm}^{3}$ and $b=$ $2.49 .10^{5} \mathrm{~g} / \mathrm{cm}^{3}$.

\subsection{NO adsorption/desorption experiments for balancing of NO concentration fluctuations}

Experiments, at which NO (1 mol\%) was present at the adsorption column inlet for a certain time period alternating with pure nitrogen, were done. This mode of NO concentration fluctuations was repeated in 7-hour periodic cycles simulating periodic process. The purpose of these experiments was to find conditions under which the bed of $\mathrm{AC}$ was able to damp the NO concentration fluctuations in the nitrogen entering the $\mathrm{AC}$ bed and achieve the balancing of the NO concentration in the outlet gas within the selected cycle.

For each experiment, a mean NO concentration at the column inlet during cycle duration $\left(\bar{c}^{o}\right)$ was calculated:

$$
\bar{c}^{o}=c^{o} \cdot \frac{\tau_{N O}}{\tau_{c y c l e}}
$$

where $c^{o}$ is the concentration of NO at the column inlet, $\tau_{c y c l e}$ the duration of one cycle and $\tau_{N O}$ part of the cycle when there was only $\mathrm{N}_{2}$ flowing. 
It was assumed that for a certain value of NO mean input concentration $\bar{c}^{o}$, a minimum value of residence time, at which balancing was achieved, could be determined. The condition for the residence time considered greater or equal to minimum residence time was such that the maximum according to square-wave change of the input concentration did not appear during output concentration in the selected cycle of measurement.

The experiments were carried out so that it was being determined what the minimum residence time necessary for balancing at the input of all NO (1 mol\%) during $60 \mathrm{~min}$ from the 7-hour cycle (i.e. $\bar{c}^{o}=1428 \mathrm{ppm}$ NO) was. The NO concentration at the column outlet was considered balanced if it did not demonstrate a local maximum with a deviation higher than $5 \%$ of the measured average NO concentration. It is evident that balancing was only achieved with a residence time of 9.4 min and higher.

Similar experiments testing the effect of time period length $\left(\tau_{N O}=30 \mathrm{~min}\right.$ and $\tau_{N O}=$ $15 \mathrm{~min})$, in which NO (1 mol\%) was present in the input gas during the 7-hour cycle, were carried out. The summary of results is shown in Table 1 , measurements $1 \mathrm{~A}-1 \mathrm{C}$ and $2 \mathrm{~A}-2 \mathrm{C}$, respectively. We can conclude that if the gas containing $1 \mathrm{~mol} \% \mathrm{NO}$ is entering the column for 30 and $15 \mathrm{~min}$, a minimum residence time of 5.6 and $3.1 \mathrm{~min}$ is necessary for balancing. An orientation graph (Fig. 3) depicting the dependence of mean NO concentration $\bar{c}^{o}$, which can be balanced at the quoted minimal residence time, was made from the obtained results. The dependence is valid for the used laboratory conditions, i.e. repeating 7-hour cycles of NO presence in the inlet gas and superficial velocities $0.3-1 \mathrm{~cm} \mathrm{~s}^{-1}$. The minimal residence time increases with increasing average NO concentration; the area below the curve represents the conditions at which the activated carbon bed damps efficiently the NO concentration fluctuations.

The explanation of the processes running in the $\mathrm{AC}$ bed is as follows: There is adsorption and desorption of NO occurring alternately in the bed of saturated AC. When the 
periodically fluctuating NO concentration at the inlet is low, the concentration at the outlet is higher due to desorption. At the same time, a part of the adsorptive capacity of AC bed is released. The released adsorptive capacity is utilized for the adsorption of NO at the time when the concentration at the inlet is high. In order to achieve a practically total balancing of the outlet concentration, the adsorptive capacity released, when the inlet concentrations are low, must be high enough. For given adsorbent and $\bar{c}^{o}$, the extent of attenuation is dependent on the residence time. It implies from the LDF model that the extent of attenuation at given residence time is determined by the value of $q^{o} / \bar{c}^{o}$ at the feed conditions for adsorbents with different adsorption capacity. The reason is non-linear equilibrium isotherm for adsorption of NO on AC. A higher adsorption capacity improves the effectiveness of adsorbent bed for handling fluctuating input loads [2].

\section{Conclusions}

The activated carbon was filled in the adsorption column and cyclic NO concentration fluctuations ( $1 \mathrm{~mol} \% \mathrm{NO}$ in $\mathrm{N}_{2}$ ) were applied in the column inlet at laboratory conditions. The experiments confirmed the possibility of balancing these concentration fluctuations during flow of the gas through an activated carbon bed. Langmuir equilibrium isotherm described NO adsorption on AC. The possible application of obtained results is in the balancing of timevariable NO concentrations releasing in waste gases from periodic processes and therefore facilitates the subsequent cleaning of the waste gases. Further experiments are necessary to verify the activated carbon bed behavior for more complex gas mixture containing oxygen and water vapor corresponding to the real waste gases. Our future work will be focused on mathematical prediction of observed experimental data of the NO adsorber dynamics.

\section{Acknowledgements}


This work was realized under the financial support of Ministry of Industry and Trade of the Czech Republic; project No. 2A-2TP1/061.

\section{References}

[1] J. Červenka, L. Obalová, Method of leveling of concentration fluctuations of compound or compounds in the flowing gas. CZ patent 2005-434, 2007.

[2] K. Eguchi, M. Watabe, M. Machida, H. Arai, Selective removal of NO by adsorption in mixed oxide catalysts, Catal. Today 27 (1996) 297-305.

[3] R. Pietrzak, Sawdust pellets from coniferous species as adsorbents for $\mathrm{NO}_{2}$ removal, Bioresource Technol. 101 (2010) 907-913.

[4] J.D. Henao, L.F. Cordoba, C.M.de Correa, Theoretical and experimental study of $\mathrm{NO} / \mathrm{NO}_{2}$ adsorption over Co-exchanged type-A zeolite, J. Mol. Catal. A 207 (2004) 195-204.

[5] W.J. Zhang, S. Rabiei, A. Bagreev, M.S Zhuang, E. Rasouli, Study of NO adsorption on activated carbons, Appl. Catal. B 83 (2008) 63-71.

[6] Y.-W. Lee, D.-K. Coi, J.-W. Park, Performance of fixed-bed KOH impregnated activated carbon adsorber for $\mathrm{NO}$ and $\mathrm{NO}_{2}$ removal in the presence of oxygen, Carbon 40 (2002) 1409-1417.

[7] A. Claudino, J.L. Soares, R.F.P.M. Moreira, H.J. José, Adsorption equilibrium and breakthrough analysis for NO adsorption on activated carbons at low temperatures. Carbon 42 (2004) 1483-1490.

[8] X.L. Xu, Z.H Chen, W.K. Chen, J.Q. Li, Theoretical study of NO dimer adsorption and dissociation on the $\mathrm{CuCr}_{2} \mathrm{O}_{4}$ (100) surface, Chinese J. Structur. Chem. 27 (2008) 927-932. 
[9] Md. Amanullah, S. Farooq, S. Viswanathan, Modeling and Simulation of a Biofilter. Ind. Eng. Chem. Res. 38 (1999) 2765-2774.

[10] Md. Amanullah, S. Viswanathan, S. Farooq, Equilibrium, Kinetics, and Column Dynamics of Methyl Ethyl Ketone Biodegradation. Ind. Eng. Chem. Res. 39 (2010) 3387-3396.

[11] S. Sumathi, S. Bhatia, K.T. Lee, A.R. Mohamed, Adsorption isotherm models and properties of $\mathrm{SO}_{2}$ and NO removal by palm shell activated carbon supported with cerium (Ce/PSAC). Chem. Eng. J. 162 (2010 194-200.

[12] M.F. Edwards, J.F. Richardson, Gas Dispersion in Packed Bed. Chem. Eng. Sci. 33 (1978) 1375-1384. 


\section{Figure captions}

Fig. 1 Breakthrough curves for the adsorption of NO on AC.

Conditions: $0.8 \mathrm{~g} \mathrm{AC}$, column diameter of $0.5 \mathrm{~cm}$, particle diameter of $1 \mathrm{~mm}$

Fig. 2. Time dependence of NO concentration at the column inlet and outlet.

Conditions: $\bar{c}^{o}=1428 \mathrm{ppm} \mathrm{NO}, \tau_{N O}=60 \mathrm{~min}, 1430 \mathrm{~g} \mathrm{AC}$, column diameter of $5 \mathrm{~cm}$, particle diameter of 4 $\mathrm{mm}$.

Fig. 3. The dependence of average NO concentration on minimum residence time at which the balancing of concentration fluctuations of NO at the inlet occurs. 


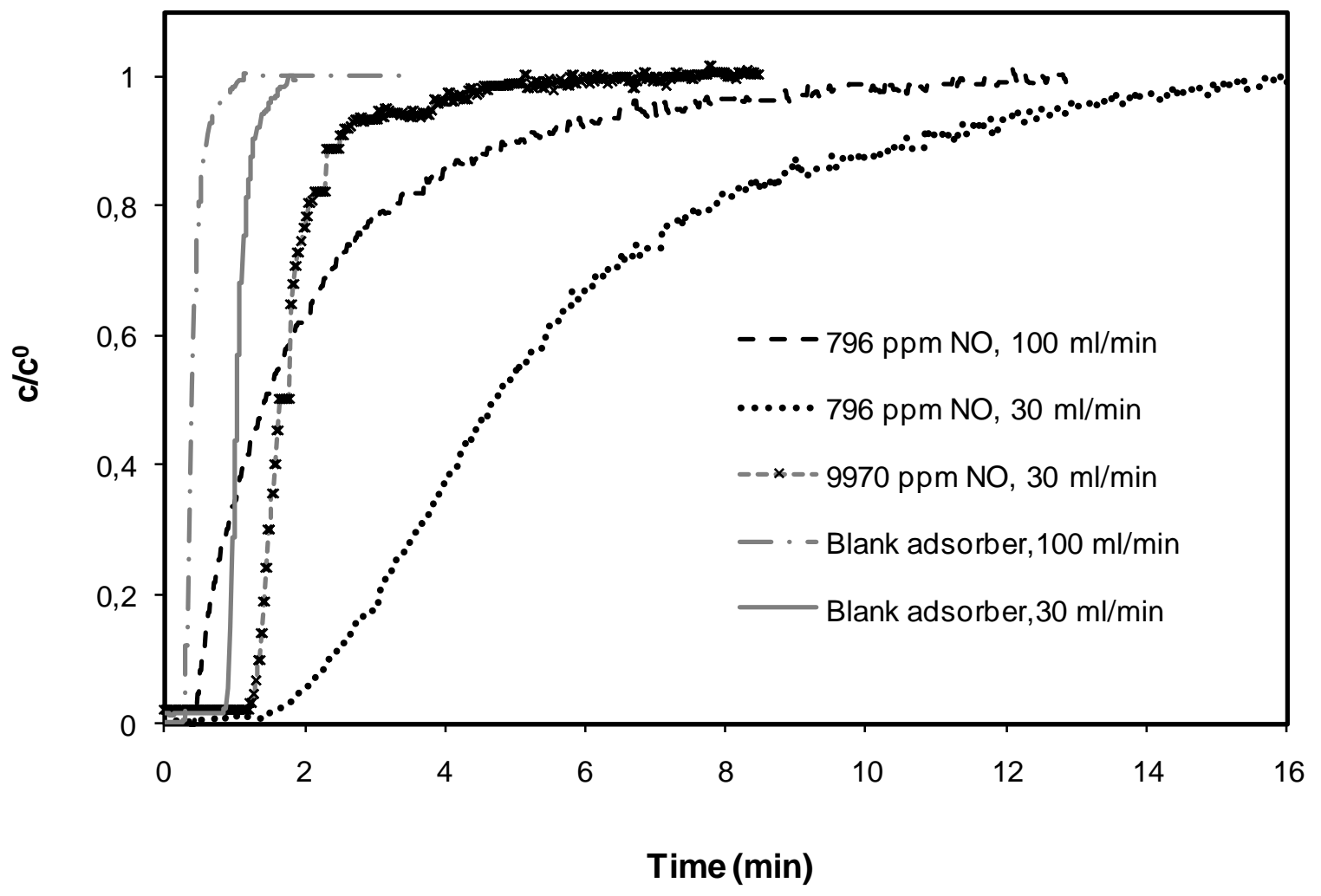

Fig. 1 

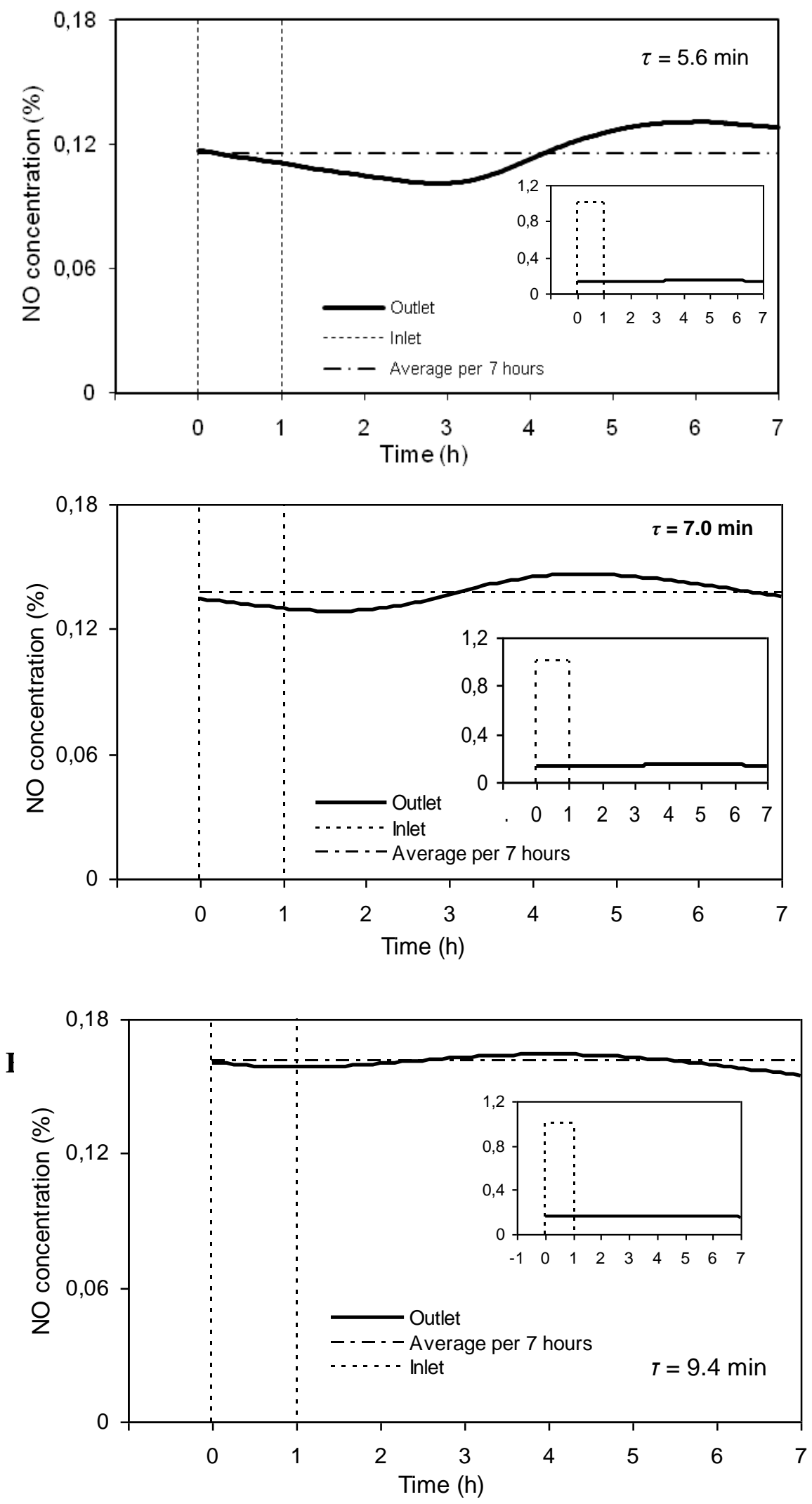


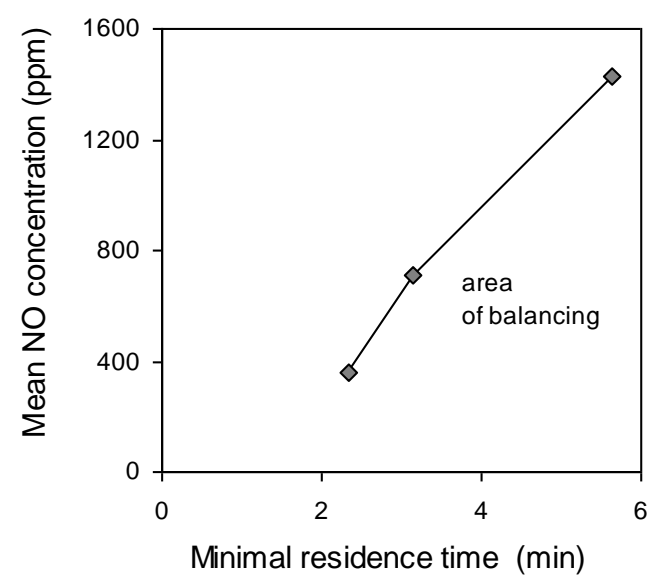

Fig. 3 
Table 1

Results of experiments for balancing of NO concentration fluctuations

\begin{tabular}{|c|c|c|c|c|c|c|c|}
\hline & $\begin{array}{c}\bar{c}^{o} \\
(\mathrm{ppm})\end{array}$ & $\begin{array}{c}\bar{c} \\
(\mathrm{ppm})\end{array}$ & $\begin{array}{c}\tau_{N O} \\
(\min )\end{array}$ & $\begin{array}{c}\tau \\
(\min )\end{array}$ & $\begin{array}{c}\mathrm{N}_{2} \text { flow } \\
\left(\mathrm{cm}^{3} / \mathrm{min}\right)\end{array}$ & $\begin{array}{c}v \\
(\mathrm{~cm} / \mathrm{s})\end{array}$ & Result \\
\hline $1 \mathrm{~A}$ & & & & 3.1 & 900 & 0.77 & not balancing \\
\hline $1 \mathrm{~B}$ & 714 & $652 \pm 43$ & 30 & 5.6 & 500 & 0.43 & balancing \\
\hline $1 \mathrm{C}$ & & & & 7.0 & 400 & 0.34 & balancing \\
\hline $2 \mathrm{~A}$ & & & & 2.3 & 1200 & 1.03 & not balancing \\
\hline $2 \mathrm{~B}$ & 357 & $351 \pm 83$ & 15 & 3.1 & 900 & 0.77 & balancing \\
\hline $2 \mathrm{C}$ & & & & 5.6 & 500 & 0.43 & balancing \\
\hline
\end{tabular}

